\title{
Travel mode attitudes, urban context, and demographics: do they interact differently for bicycle commuting and cycling for other purposes?
}

\author{
Jie Gao ${ }^{1}$ D $\cdot$ Dick Ettema $^{1} \cdot$ Marco Helbich $^{1} \cdot$ Carlijn B. M. Kamphuis ${ }^{2}$
}

Published online: 8 May 2019

(C) The Author(s) 2019

\begin{abstract}
This study examined whether interactions between travel mode attitudes, urbanization level, and socio-demographics were different for bicycle commuting and cycling for other purposes. Data were obtained from the 2014 wave of the Netherlands mobility panel (MPN). In total, 2673 respondents (18+years) who had recorded at least one trip on the days covered by the survey were included in the sample. Four outcomes were constructed, two of which concerned commuting-related cycling: any commuting-related bicycle usage (yes vs. no) and average cycling duration (in hours per weekday). Likewise, two similar outcome variables concerning cycling for other proposes were constructed. These outcomes were analyzed by means of Tobit regression models (cycling duration) and binary logistic models (any bicycle usage). Attitudinal factors concerning different travel modes, namely bus, car, cycling, and train, were constructed by means of factor analysis. The results showed that a positive attitude toward cycling was positively related to bicycle commuting duration, but this association was less strong among those with a positive attitude toward bus use. Having a positive cycling attitude had a weaker association with both bicycle commuting usage and duration in those who do not always have a car available. Regarding cycling for other purposes, cycling attitude had a stronger positive association with cycling duration among residents of very highly urbanized area, compared to residents of less urbanized areas. The available evidence, though limited, suggests that targeting attitudes can have a measurable impact on bicycling, but not to the same extend among all people.
\end{abstract}

Keywords Travel mode attitudes · Urbanization level · Bicycle commuting · Cycling for other purposes $\cdot$ Interactions

Jie Gao

j.gao1@uu.nl

Extended author information available on the last page of the article 


\section{Introduction}

Cycling, a clean and active transportation mode has become an increasingly important component of strategies to address issues of public health, climate change, air quality, and inner-city mobility (Oja et al. 2011; de Nazelle et al. 2011; Handy et al. 2014). The extensive literature focusing on how to increase bicycle usage (Xing et al. 2010; Heinen et al. 2011; Pucher and Buehler 2008; Fishman et al. 2015a; Dill et al. 2014) has generated many insights into the complex relationships between intrapersonal, interpersonal, and environmental aspects. Although many studies have focused on elements of the built environment as determinants of cycling behavior, it has been reported that travel-related attitudes may be equally or more important in increasing the use of bicycles (Heinen et al. 2011; Willis et al. 2015; Curto et al. 2016; Dill et al. 2014). The theory of planned behavior (TPB) developed by Ajzen (1991) is a useful way to explicitly incorporate attitudes and other psychological factors, in addition to the physical environment and sociodemographic characteristics, into models for analyzing cycling behavior (Heinen et al. 2010; Willis et al. 2015).

Thus far, various European studies have directly investigated attitudes toward cycling. For instance, a Dutch study found that attitudes toward cycling are more positive and prominent for cyclists covering longer distances in comparison to those making shorter trips (Heinen et al. 2011). Using a sample drawn from British university employees, Gatersleben and Uzzell (2007) found that regular cyclists had the most positive attitudes toward cycling. An American study (Dill and Voros 2007) also confirmed the association between positive attitudes toward cycling and transportation cycling. Ewing and Cervero (2010) conducted a meta-analysis of 62 studies on the built environment- travel behavior relation and identified only nine of them that include "attitudinal variables" in predicting walking and cycling behavior. Specifically, these studies consistently reported significant relationships between attitudes and active travel. Dill et al. (2014) concluded that the built environment and demographics are important in influencing behavior, largely because they influence attitudes, which in turn help predict how often someone bikes or walks from home. Regarding attitudes toward car use, for example, studies found that enjoying cycling had a positive effect on cycling for transportation, whereas not enjoying driving (Dill and Voros 2007) and limiting driving (Xing et al. 2010) are correlated with cycling for transportation. Regarding commuting, Miller and Handy (2012) found a potential substitutional relationship between cycling and driving. Positive attitudes toward bicycling and negative attitudes toward driving are associated with university employees cycling to work, after controlling for trip distance (Miller and Handy 2012). The attitudes of people towards transport modes other than car are important for policy makers having the intention to increase transit ridership, walking, or cycling. Nevertheless, the associations between cycling and attitudes toward other travel modes received limited attention to date.

However, attitudes may not always predict travel behavior directly. Some studies also claimed that travel-related attitudes influence travel behavior indirectly through their residential location choice. People might select themselves in neighborhoods facilitating the use of their preferred travel mode (Cao et al. 2009; Schwanen and Mokhtarian 2005). However, choice of residential environment not always corresponds with the intended travel behavior. For example, Cao et al. (2006) revealed differences in travel behavior across these two types of neighborhoods (suburban vs. urban areas) were partly attributable to attitudinal factors rather than the built environment. Additionally, people living in suburban areas, may be forced to use the car as destinations are beyond walking or cycling distance (Schwanen and Mokhtarian 2005; De Vos and Witlox 2016). 
A different perspective on attitudes and behavior is discussed in socioecological models, which posit that, theoretically, the effect of attitudes on behavior also depend on other individual characteristics (e.g., age, gender, education, and income) or environmental circumstances (e.g., urbanization levels) (Sallis et al. 2015). Further, ecological models suggest that the combination of individual (i.e., intrapersonal, sociodemographic) and environmental variables will best explain physical activity. That is, individual and environmental variables may have an interaction effect with attitudes on travel behavior. For example, a positive stance toward a certain mode of transportation will result in a higher use of that mode, as long as the use of this mode is not restricted by elements such as urban and suburban neighborhoods (De Vos and Witlox 2016). Bhat and Guo (2007) examined the interaction effects between density and demographics on cycling behavior. They found that low-income residents living in the areas with a high employment density tend to have a lower propensity to cycle than their counterparts in similar areas. However, these differences might also be due to varying travel-related attitudes. Furthermore, the effect of a certain travel-related attitude on cycling may depend on preferences regarding other transportation modes. It has been suggested that car users who also use other modes, such as the bicycle, may develop different attitudes toward cycling compared to those who solely use a car (Diana and Mokhtarian 2009). Although theories suggest that attitude toward cycling moderate the effects of socio-demographics and environmental factors on cycling behavior, empirical studies in the domain of cycling have largely ignored the interaction terms of travel-related attitudes with sociodemographic and environment characteristics.

Despite the recognition of the socioecological nature of travel behavior (Sallis et al. 2015), only a few scholars have studied the interaction effects of attitudes with sociodemographic and environmental characteristics, and their findings are inconsistent (Ding et al. 2012; Beenackers et al. 2013, 2014; Carlson et al. 2012). In general, both compensatory and synergetic interaction mechanisms can be at play. For example, a compensatory mechanism was found in that having a positive attitude toward walking makes the effects of urban form layout less important to leisure-time walking (Beenackers et al. 2014). On the contrary, the synergetic mechanism showed that the environment is more important to physical activity among those who have more positive psychological characteristics (Carlson et al. 2012). Likewise, the mechanism assumes a synergy between interpersonal and built environment characteristics and attitudes toward cycling. For example, it may be assumed that retired people who have more free time and a positive attitude toward cycling will cycle more. In contrast, a positive attitude toward cycling in people who have a car, could lead to less cycling than in people with no car available. This may indicate that interaction effects are likely to be complex and behavior-specific. Besides, regarding competitive mechanism, attitudes toward different modes also have an effect on cycling behavior, although most studies have neglected interactions between cycling attitudes and attitudes toward other travel modes. To our knowledge, only a few studies investigated the interaction effect between the built and social environment on cycling without considering cycling attitudes (Bourke et al. 2018; Wang et al. 2017; D’Haese et al. 2016). A Belgian study on children found an interaction effect between support from friends and neighborhood walkability on cycling in leisure time (D'Haese et al. 2016). This study also showed that friend support moderated the relationship between walkability and cycling in leisure time; however the effect size of this interaction was minor.

The interaction effects of travel-related attitudes with trip characteristics may differ by trip purpose. Different mechanisms may trigger and influence cycling for these different purposes (Scheepers et al. 2013), especially for bicycle commuting and cycling for other purposes (Barnes and Krizek 2005), as trips to work typically comprise a significant 
portion of a worker's total weekly trips (Stinson and Bhat 2004). For example, commuting cyclists are much more sensitive to factors such as travel time due to busy activity agendas than people in leisure time. In addition, since bicycle commuting is a form of non-discretionary travel, it is likely to be impacted by different factors than those impacting trips for other purposes (Heinen et al. 2010). For instance, commuters may have fixed work hours, nonflexible options for their departure time, route choice, and few feasible commute mode choices, so a strong motivation is needed for them to switch to or sustain cycling. So far, while some studies showed that cycling attitudes are also strongly associated with cycling distance and the choice of bicycle commuting (Handy et al. 2010; Heinen et al. 2011), there has been limited investigation of how the interaction effects of attitudes with sociodemographic and environmental characteristics vary across bicycle commuting and other purposes.

Hence, the aim of the present study was to fill this gap by investigating the extent to which the relation between sociodemographic characteristics, urbanization level, and attitude toward alternative travel modes on the one hand and cycling behavior (bicycle commuting and cycling for other purposes) on the other hand interacts with attitudes toward cycling. The conceptual framework for this study (Fig. 1) is partly based on previous studies (Xing et al. 2018; Willis et al. 2015).

\section{Materials and methods}

\section{Data source and sample}

Data were obtained from the Netherlands Mobility Panel (MPN), which was set up to establish short- and long-term dynamics in the travel behavior of individuals and households, and to determine how changes in personal and household characteristics and in other travel-related factors (e.g., reduced taxes on sustainable transportation, or changes in land use) correlate with changes in travel behavior (Hoogendoorn-Lanser et al. 2015). Socioeconomic attributes for individuals and their households were collected through individual questionnaires. Participants with a completed questionnaire were also invited to keep an online trip diary for three successive days (including weekend days). For each respondent,

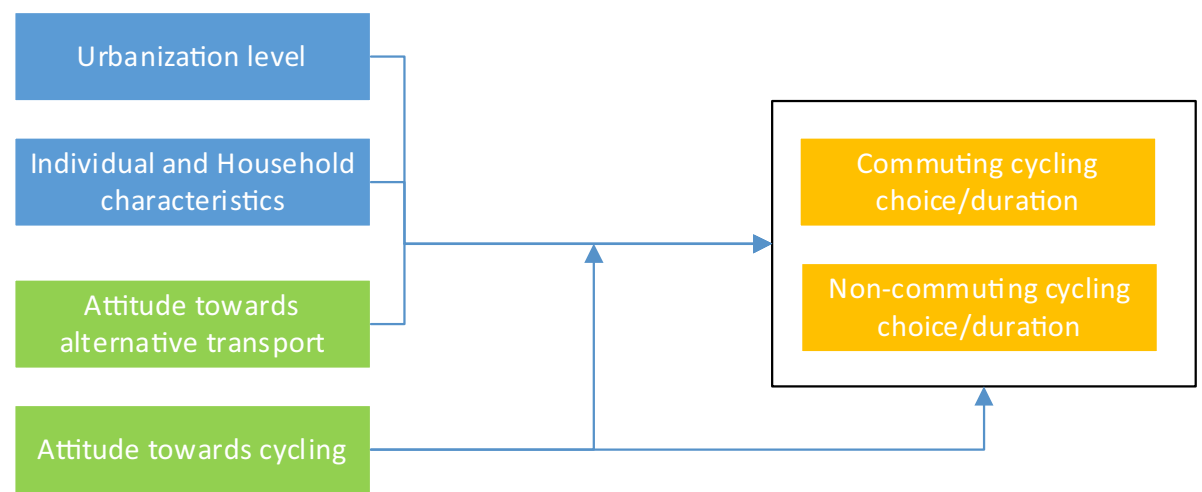

Fig. 1 Conceptual framework 
the diary provides information about all trips the respondent made (e.g., transportation modes, trip duration, distances, trip purposes, travel companionship and delays).

The present study is based on data from the panel survey 2014 of MPN, as this wave had a particular focus on travel-related attitudes. The sample selected for this study only includes participants who recorded travel data and were aged over 17 years (the age at which it is legal to drive a car in the Netherlands) $(\mathrm{N}=4978)$. Participants who did not complete the questionnaire were excluded $(\mathrm{N}=872)$. Participants with no opinion about attitudes toward travel modes were also excluded $(\mathrm{N}=1152)$. Also, only regular day-today trips were selected, which means that holidays trips and trips abroad were excluded $(\mathrm{N}=164)$. Finally, the weekends were excluded $(\mathrm{N}=117)$, because the decision structures related to weekday and weekend trips are different (Yang et al. 2016). As a consequence, the subsample on which the analyses presented in this paper are based comprised 2673 respondents.

\section{Outcome variables}

To describe cycling patterns, four outcome variables were determined. Two outcome variables concerned bicycle commuting i.e., trips to and from a place of work or study. For bicycle commuting, we investigated both whether participants used their bike at all for commuting (i.e., any bicycle usage, yes vs. no) and the average daily bicycle commuting duration in hours per day (cycling duration; continuous variable). Likewise, the other two outcome variables (bicycle usage and average daily cycling duration in hours per day) for other purposes were identified. Bicycle usage represented whether participants chose to cycle at all. Daily cycling duration represents how many minutes people cycle per day, an indicator of the mobility of people going about their day-to-day lives.

\section{Travel mode attitudes}

The MPN 2014 measured respondents' attitudes toward driving, cycling, trains, and buses. For each travel mode respondents indicated to what extent they regard it as comfortable, relaxing, time saving, flexible, and pleasurable, and their personal impression of the travel mode. The attitudes represent the degrees to which people favor the respective modes. The items were measured by a 5-point Likert scale ranging from 1 (=strongly disagree) to 5 (= strongly agree). The questionnaire contained 28 statements on various attitudinal dimensions. Principal components analysis (PCA) with an orthogonal rotation (i.e., varimax method) was used to reduce the dimensionality of the subset of attitude measures and create continuous linear composite factors for analysis (Bryant 1995; Härdle and Simar 2007).

\section{Sociodemographic and spatial context characteristics}

Individual characteristics were based on self-reports from MPN 2014 and were considered done previously (de Haas et al. 2018; Gao et al. 2018). Age was divided into six categories: 18-29, 30-39, 40-49, 50-59, 60-69, and 70-80 years. We categorized gross household income per year into low $(<€ 26,000)$, medium $(€ 26,000-65,000)$, and high $(>€ 65,000)$. Educational attainment was stratified into three categories: low (primary school and lower general secondary school), medium (upper-division secondary school), and high (college and university) (CBS 2016). Due to the low proportion of the other categories (i.e., unemployed, retired, 
and housewife/husband) among the sample, the employment status was classified into three groups: employed, student, and retired or other unemployed. We also controlled for numerous other key variables, including gender, presence of children within household (under 12 years old), and car availability (i.e., always a car available, not always a car available, and no car).

There is some evidence of associations between cycling behavior and built environment characteristics such as accessibility of employment, population density and residential location (Ewing and Cervero 2010; Wong et al. 2011). Among them, population density can be considered as a key element of availability of local destinations (e.g., shops and services) and is related to other built environmental attributes such as housing type, street pattern, access to public transport, hence people's travel behavior (Cervero and Kockelman 1997). Therefore, in this study, the spatial context was measured by urbanization level, which was classified into four categories according to the population density: very highly urbanized ( $>2500$ inhabitants $/ \mathrm{km}^{2}$ ), highly urbanized (1500-2500 inhabitants $\left./ \mathrm{km}^{2}\right)$, moderately urbanized (1000-1500 inhabitants $\left./ \mathrm{km}^{2}\right)$, less urbanized/rural areas $\left(<1000\right.$ inhabitants $\left./ \mathrm{km}^{2}\right)$.

\section{Statistical analyses}

Descriptive statistics were used to summarize the data. Pearson correlation coefficients were used to assess multicollinearity among the covariates. Correlations larger than \pm 0.8 are considered problematic (Freedman et al. 1991). We added the correlation table as an Appendix (Table 5).

Multivariate regression analyses were performed to relate the sociodemographic variables, urbanization level, and travel mode attitudinal factors to measures of cycling duration and daily bicycle usage for commuting and other purposes. Cycling duration was investigated in a Tobit regression analysis, as it better handled the dependent variables' lack of negative values and excess of zeros due to people not making any cycling trips on the days covered by the survey (Greene 2003). For daily bicycle usage, a binary logistic model was used. Because we were dealing with data consisting of data for multiple days for one person, the data may have violated the independence assumption. The estimation of equal robust standard errors per participant corrected for intragroup correlation (Wooldridge 2010).

Separate models for commuting and other purposes cycling duration and bicycle usage were used to test the interaction of each of the included variables with cycling attitudinal factors. The first set (models $1 \mathrm{a} / 2 \mathrm{a} / 3 \mathrm{a} / 4 \mathrm{a}$ ) contained all the sociodemographic variables, urbanization level variable, and the individual travel mode attitudinal factors. Subsequently, to explore the interactions, the second set (models $1 \mathrm{~b} / 2 \mathrm{~b} / 3 \mathrm{~b} / 4 \mathrm{~b}$ ) was estimated for each outcome variable that added the interactions with attitudes toward cycling based on the first model. All models were estimated using STATA/SE 15.0 (StataCorp, College Station, Texas).

\section{Results}

\section{Descriptive analysis}

Table 1 presents descriptive statistics for the total sample, as well as descriptive statistics for respondents who engaged in bicycle commuting and cycling for other purposes separately. Of the sample, $52.9 \%$ reported any cycling during the survey days, and the average daily cycling duration was $0.27 \mathrm{~h}$ and 1.1 cycling trips per day among all participants. The mean number of bicycle commuting trips for those cycling was 1.5 , which was less 
than cycling trips for other purposes (2.1). Specifically, about $21.8 \%$ of the total sample engaged in bicycle commuting, while $38.3 \%$ of respondents reported cycling for other purposes (e.g., of the latter category, $54.1 \%$ was related to shopping, $58.1 \%$ to leisure, and $36.9 \%$ to other purposes, as some participants engaged in multiple non-commuting trips). Women made up $54.2 \%$ of the total sample but accounted for $59.8 \%$ of all individuals who reported any bicycle commuting and for $62.8 \%$ of all individuals who reported cycling for other purposes. Thus, women were more likely to cycle than the men, especially for non-commuting purposes, which is consistent with a previous study (Garrard et al. 2008). More young adults reported bicycle commuting (35.3\% for the category 18-29 years), while more elderly people reported cycling for other purposes $(24.4 \%$ for the category $60+$ years). Individuals who reported bicycle commuting were less likely to have dependent children in their households $(15.6 \%)$ or to always have a car available (41.4\%), and were more likely to be students $(22.3 \%)$ have low household incomes $(26.7 \%)$ and live in highly or very highly urbanized areas. Individuals who reported cycling for other purposes were more likely to be retired or unemployed (37.1\%), and to not always have a car available $(29.2 \%)$ or never have a car available $(17 \%)$.

\section{Factor analysis on attitudinal factors}

Exploratory factor analysis was used to identify the attitudinal factors related to different travel modes. Items with low communalities $(<0.5)$ were iteratively excluded, leaving 25 of 28 attitudinal characteristics to test for underlying constructs. Four factors (i.e., attitude toward bus/cycling/car/train) contributed $61.36 \%$ to the cumulative variance, and this provided interpretable factors. All Cronbach's alpha coefficients showed high reliability $(\alpha=0.8)$ (Hair et al. 2009), indicating that internal consistencies are acceptable, and it was therefore acceptable to use each factor instead of the original indicators (Table 2).

\section{Multivariate regression analysis}

\section{Bicycle commuting}

As shown in Table 3, both the estimated models $1 \mathrm{~b}$ and $2 \mathrm{~b}$, with a McFadden pseudo- $\mathrm{R}^{2}$ of 0.185 for bicycle commuting usage and 0.166 for bicycle commuting duration, fit the data moderately, compared to models $1 \mathrm{a}$ and $2 \mathrm{a}$, separately. This indicated the reasonability of considering interactions between attitude toward cycling and other environmental and individual characteristics.

Regarding both bicycle commuting usage and duration, two significant interactions were observed in regression models (model $1 \mathrm{~b}$ and $2 \mathrm{~b}$ ). Among those with children less than 12 years of age, a positive attitude toward cycling was less strongly associated with bicycle commuting usage and duration than among those with no young children in the household. One possible explanation is that the presence of children in a household may mean that commuters are more time pressed, as they have to take care of children in the morning and pick them up from school in the afternoon, or have to combine other childcare-related activities. This interaction could indicate the existence of the compensatory mechanism proposed in the introduction. Another compensatory mechanism was also found: the negative effect of car availability on cycling is weaker for those with a positive attitude towards cycling. This indicates that commuters with a car available need a stronger motivation to cycle, as commuting travel is a form of non-discretionary travel, and acquiring a car would 
Table 1 Descriptive statistics

\begin{tabular}{llll}
\hline Variables & $\begin{array}{l}\text { Total sample } \\
(\mathrm{N}=2673)\end{array}$ & $\begin{array}{l}\text { Respondents reporting } \\
\text { any bicycle commuting } \\
(\mathrm{N}=584)\end{array}$ & $\begin{array}{l}\text { Respondents report- } \\
\text { ing any cycling } \\
\text { for other purposes } \\
(\mathrm{N}=1023)\end{array}$ \\
\hline
\end{tabular}

\section{Dependent variables}

Mean cycling duration (hours) (SD) 0.27 (0.52)

$0.44(0.43)$

$0.46(0.62)$

Mean number of cycling trips (SD) 1.1 (1.6)

$1.5(0.8)$

$2.1(1.5)$

Socioeconomic characteristics

Age

$$
\text { 18-29 }
$$

$24.4 \%$

$35.3 \%$

$22.7 \%$

30-39

$15.2 \%$

$13 \%$

$13.8 \%$

40-49

$21.4 \%$

$20 \%$

$19.3 \%$

50-59

$20.6 \%$

$22.9 \%$

$20.1 \%$

60-69

$10.7 \%$

$6.8 \%$

$14.2 \%$

$70+$

$7.8 \%$

$1.9 \%$

$10.2 \%$

Gender

Male

$45.8 \%$

$40.2 \%$

$37.2 \%$

Female

$54.2 \%$

$59.8 \%$

$62.8 \%$

Education

Low
Medium
High

Gross household income

$$
\begin{aligned}
& <€ 26,000 \\
& € 26,000-65,000 \\
& >€ 65,000
\end{aligned}
$$

Children $<12$ years

No

Yes

$80.7 \%$

$19.3 \%$

$61.5 \%$

$11.2 \%$

$27.3 \%$

$64.4 \%$

$22.6 \%$

$13.1 \%$

No car available

Municipal urbanization level

Very highly urbanized

Highly urbanized

$18.9 \%$

$28.6 \%$

$23.6 \%$

$28.8 \%$ 


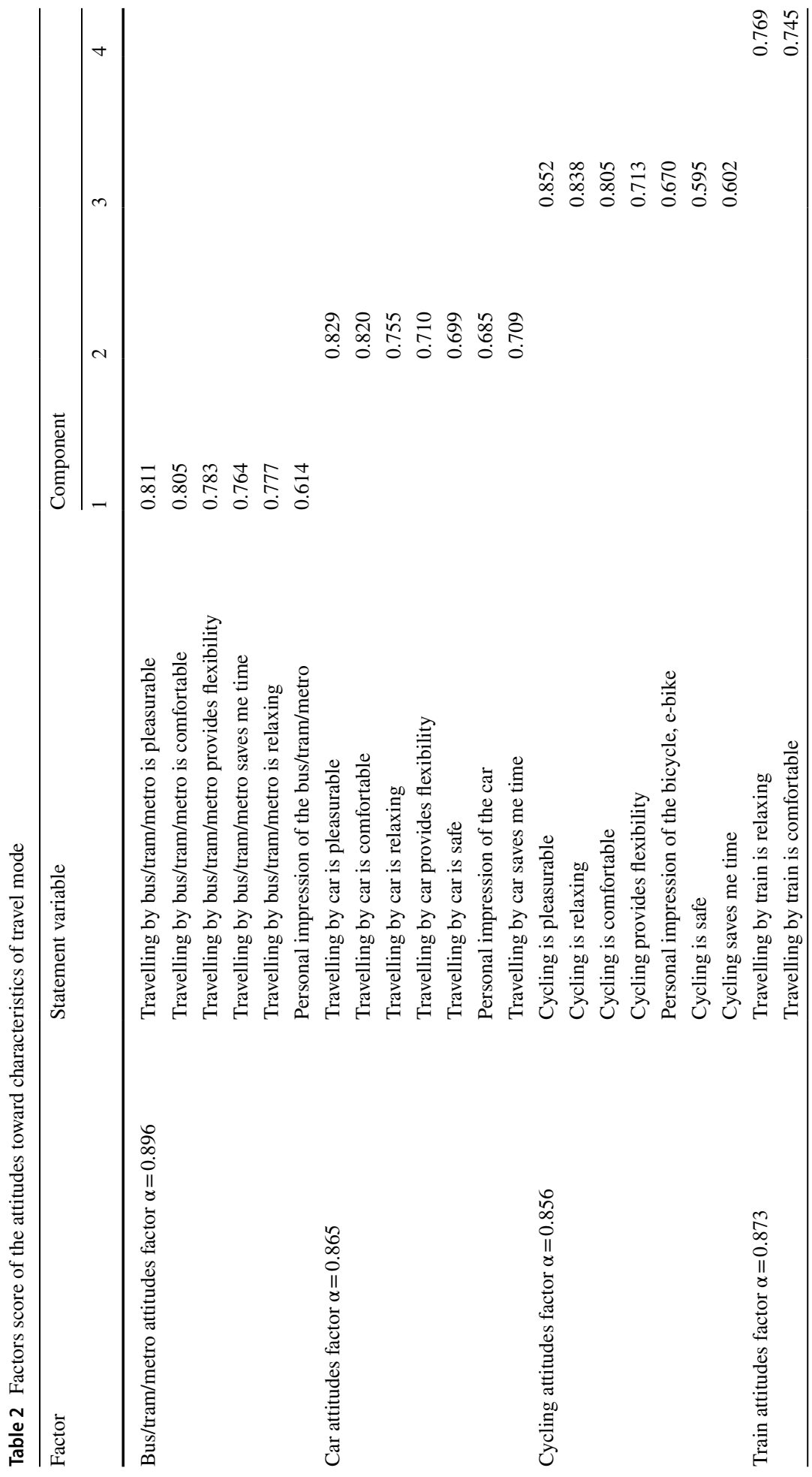




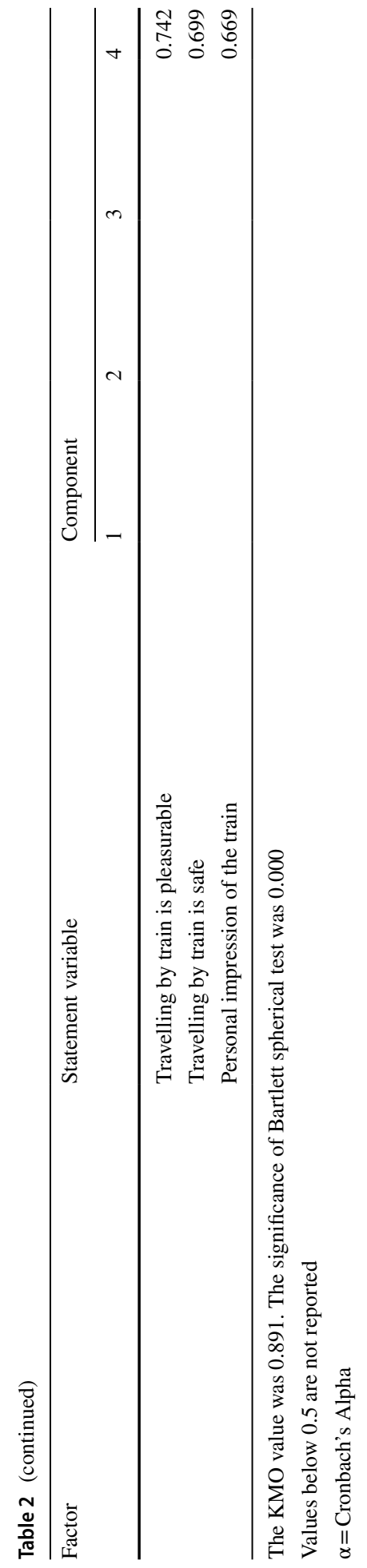




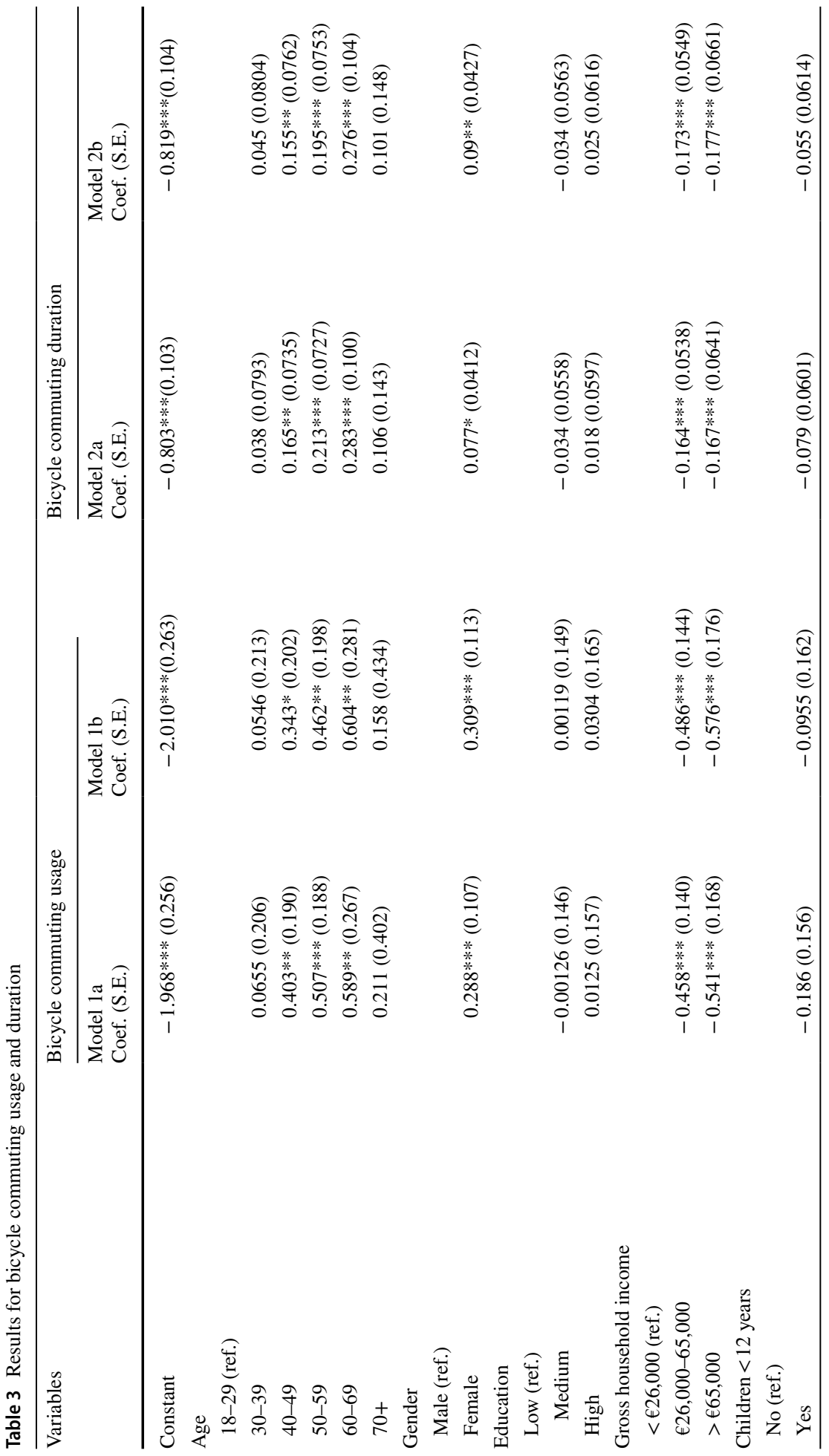




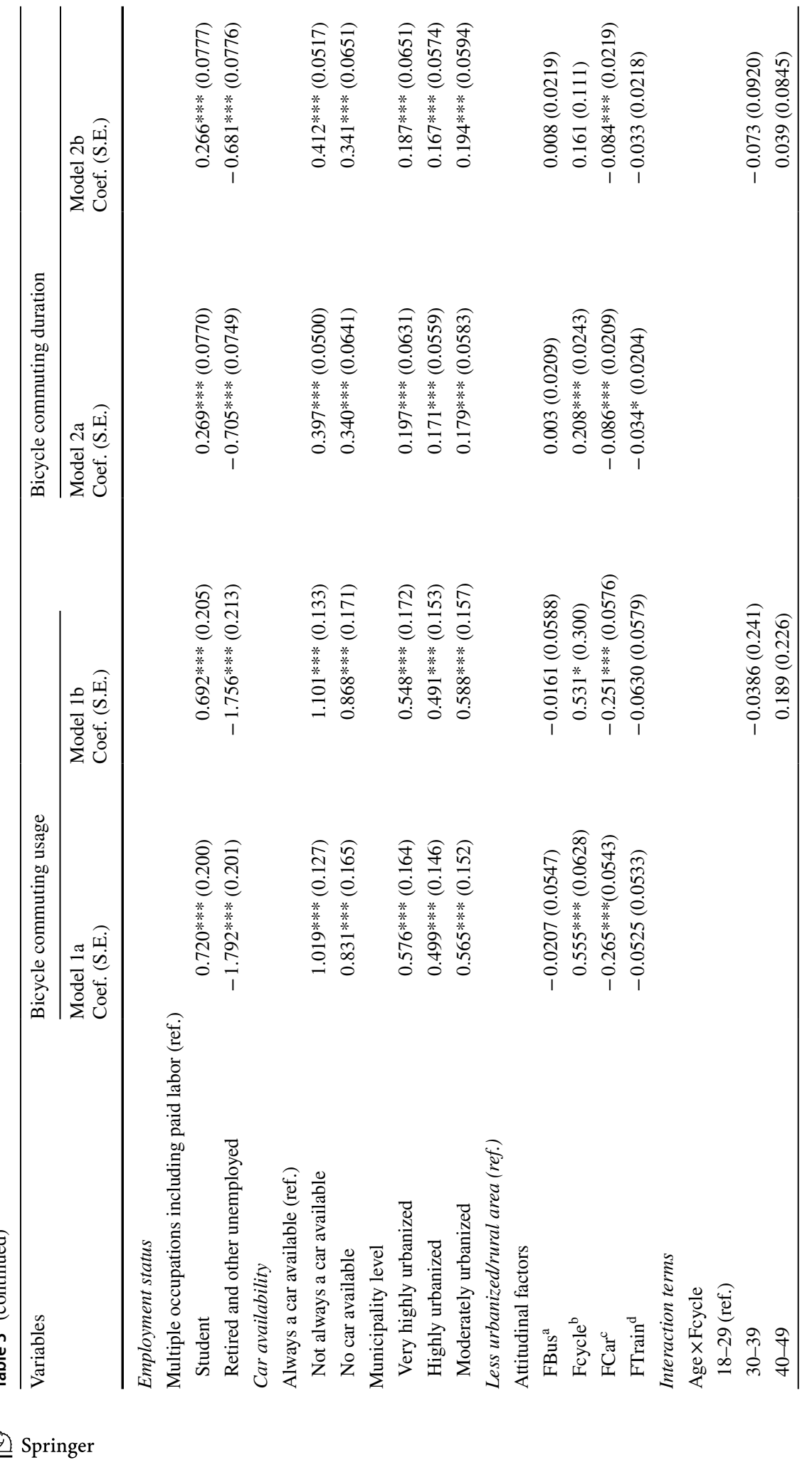




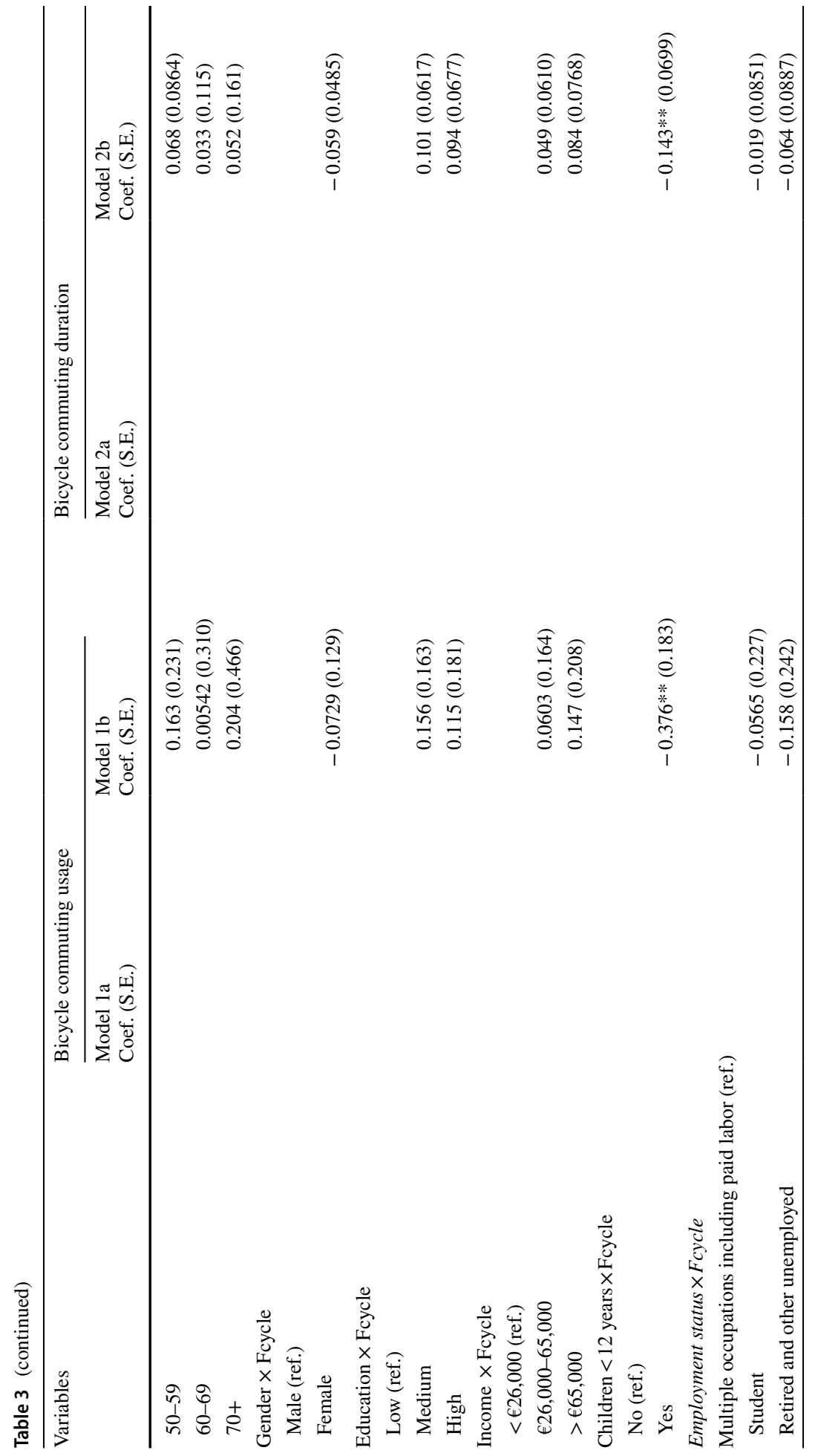




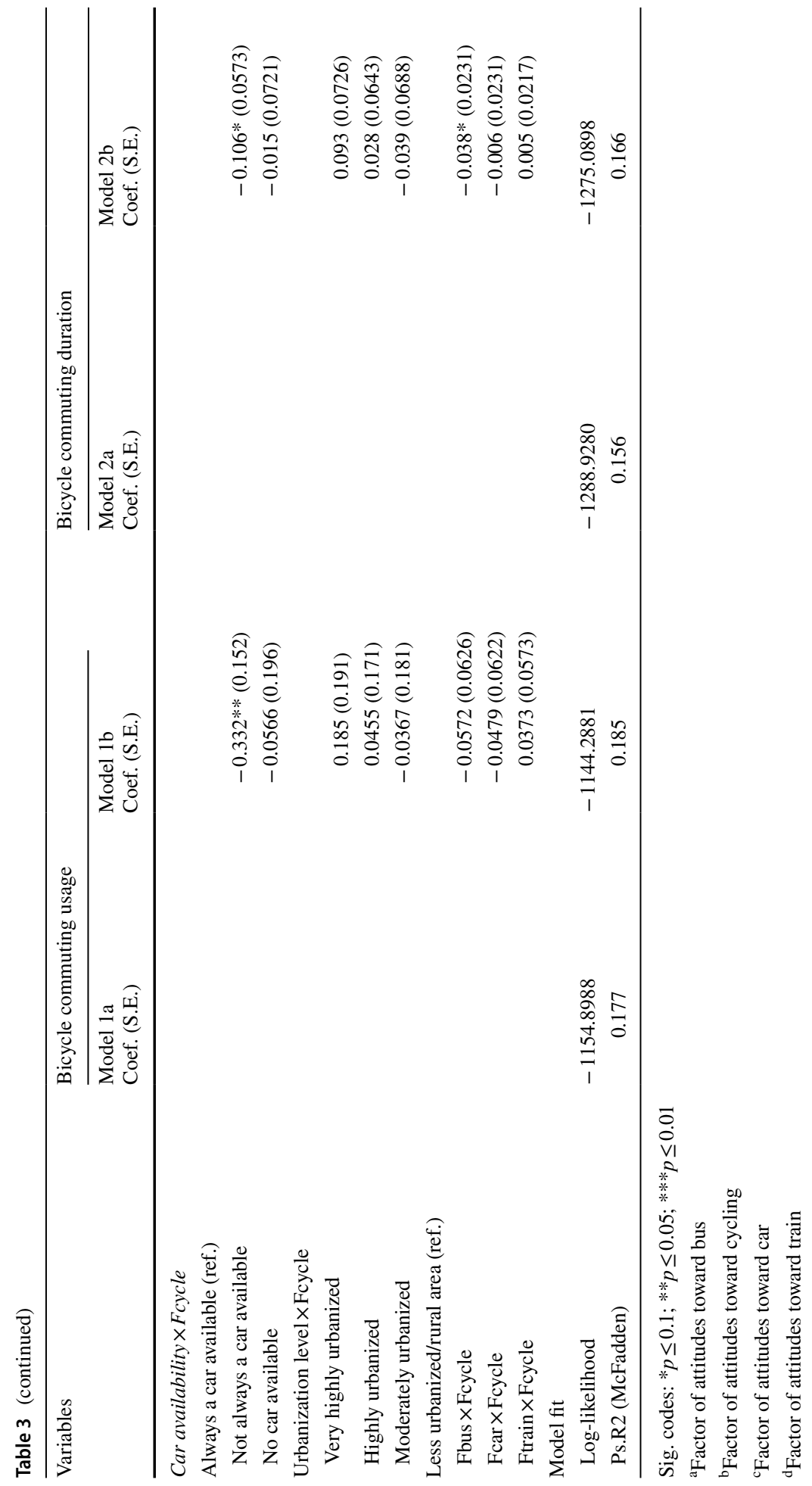

\section{Springer}


probably increase the range of choice options of the commuters (Oakil et al. 2016; Piatkowski and Marshall 2015), and thus influence bicycle usage (Fu and Farber 2017).

Having a positive cycling attitude had a weaker association with bicycle commuting among those with a positive attitude toward using buses, compared to those with a less positive attitude toward using buses. This suggests a competition between these travel modes. In particular, the relationship between attitude (toward cycling) and behavior (cycling) is weaker if an alternative behavior (take the bus) is more attractive. As no other study could be identified that investigated the interaction effects of cycling attitude and attitudes toward other transportation modes on bicycle commuting, it is hard to compare results. However, one possible explanation is that in a short commuting distance, both riding a bus and cycling are attractive to commuters, thus leading to a competitive relationship (Ettema and Nieuwenhuis 2017). For instance, a well-served public transportation infrastructure around the workplace indeed helps to increase the use of buses, and thus decreases the likelihood of bicycle commuting.

\section{Cycling for other purposes}

Overall, the estimated multivariate models show a reasonable fit, according to the significant likelihood ratio $\mathrm{Chi}^{2}$ values and the $\mathrm{McFadden}$ pseudo- $\mathrm{R}^{2}$ measures. Specifically, after adding interaction variables in models $3 \mathrm{~b} / 4 \mathrm{~b}$, the McFadden pseudo- $\mathrm{R}^{2}$ is improved from 0.118 (model 3a) to 0.131 (model 3b) for cycling for other purposes model, and from 0.098 (model 4a) to 0.106 (model 4b) for model for cycling duration (see Table 4).

With respect to cycling usage and duration for other purposes, considering the interaction terms (models $3 \mathrm{~b}$ and $4 \mathrm{~b}$ ), the results show that having a positive attitude toward cycling had a stronger effect on bicycle usage for other purposes among the middle aged (50-59), senior citizens $(60-69,70+)$, and women. In particular, with regard to age groups, elderly participants $(60-69,70+)$ with a positive attitude toward cycling, cycled most. This suggests that senior citizens (60-69) and the elderly (70+) have more time to spend on cycling (Fishman et al. 2015b; Gao et al. 2017) and that cycling is an essential means of transportation for them. Also, the interactions of cycling duration for other purposes and elderly age groups suggest that the synergetic mechanism proposed in the introduction, indicating that people in advantageous situations (i.e., retired, with plenty of time), a positive attitude toward cycling encourages them to cycle more. In addition, women with a positive attitude toward cycling were found to participate in more cycling trips than men. This is because in the Netherlands, women are more likely to have a part-time job that is closer to home, and to make shorter, linked journeys to, for example, pick up/drop off children or go shopping. Therefore, they may be more likely to make more cycling trips, which is in line with previous studies (Gao et al. 2017; Garrard et al. 2008). Car is less available to women due to the same reasons, which is another possible explanation of the stronger effect of attitude on cycling for women. The interaction between cycling attitude and gender suggests another synergistic effect; if one assumes that women's activity patterns or car allocation processes in households encourage cycling among women.

Having a positive attitude toward cycling was related to more cycling for other purposes among residents of very highly urbanized area compared to those living in less urbanized areas. This indicates that a positive cycling attitude increases the duration of cycling for other purposes in very highly urbanized areas (synergetic mechanism). Finally, for individuals who live in more urbanized municipalities, their daily activities (e.g., shopping, recreation, and visiting friends) may be more convenient than they are for people living in less urbanized areas, and therefore people who have positive attitude towards cycling they may prefer to cycle. 
Table 4 Results for cycling usage and duration for other purposes

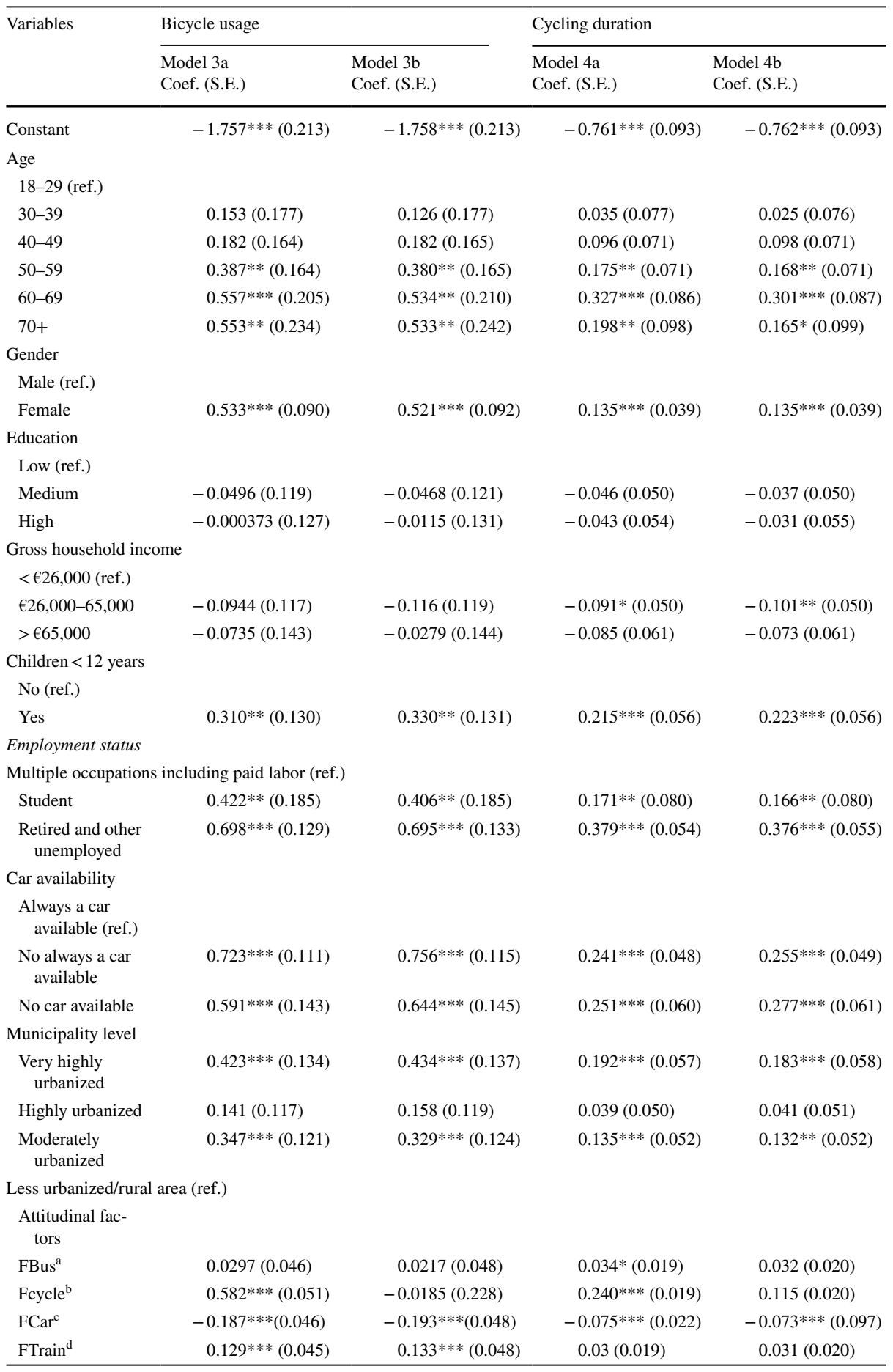


Table 4 (continued)

\begin{tabular}{|c|c|c|c|c|}
\hline \multirow[t]{2}{*}{ Variables } & \multicolumn{2}{|l|}{ Bicycle usage } & \multicolumn{2}{|c|}{ Cycling duration } \\
\hline & $\begin{array}{l}\text { Model 3a } \\
\text { Coef. (S.E.) }\end{array}$ & $\begin{array}{l}\text { Model 3b } \\
\text { Coef. (S.E.) }\end{array}$ & $\begin{array}{l}\text { Model 4a } \\
\text { Coef. (S.E.) }\end{array}$ & $\begin{array}{l}\text { Model 4b } \\
\text { Coef. (S.E.) }\end{array}$ \\
\hline \multicolumn{5}{|l|}{ Interaction terms } \\
\hline \multicolumn{5}{|l|}{ Age $\times$ Fcycle } \\
\hline \multicolumn{5}{|l|}{$18-29$ (ref.) } \\
\hline $30-39$ & & $0.177(0.196)$ & & $0.050(0.085)$ \\
\hline $40-49$ & & $0.201(0.179)$ & & $0.045(0.078)$ \\
\hline $50-59$ & & $0.318 *(0.185)$ & & $0.099(0.079)$ \\
\hline $60-69$ & & $0.515^{* *}(0.239)$ & & $0.186^{* * *}(0.095)$ \\
\hline $70+$ & & $0.623 * *(0.280)$ & & $0.224 * *(0.111)$ \\
\hline \multicolumn{5}{|l|}{ Gender $\times$ Fcycle } \\
\hline \multicolumn{5}{|l|}{ Male (ref.) } \\
\hline Female & & $0.212 * *(0.105)$ & & $0.012(0.044)$ \\
\hline \multicolumn{5}{|l|}{ Education $\times$ Fcycle } \\
\hline \multicolumn{5}{|l|}{ Low (ref.) } \\
\hline Medium & & $-0.141(0.136)$ & & $-0.118 * *(0.056)$ \\
\hline High & & $0.0139(0.149)$ & & $-0.073(0.061)$ \\
\hline \multicolumn{5}{|l|}{ Income $\times$ Fcycle } \\
\hline \multicolumn{5}{|l|}{$<€ 26,000$ (ref.) } \\
\hline$€ 26,000-65,000$ & & $0.233 *(0.134)$ & & $0.096^{*}(0.055)$ \\
\hline$>€ 65,000$ & & $-0.128(0.166)$ & & $0.009(0.071)$ \\
\hline \multicolumn{5}{|c|}{ Children $<12$ years $\times$ Fcycle } \\
\hline \multicolumn{5}{|c|}{ No (ref.) } \\
\hline Yes & & $-0.156(0.145)$ & & $-0.069(0.062)$ \\
\hline \multicolumn{5}{|c|}{ Employment Status $\times$ Fcycle } \\
\hline \multicolumn{5}{|c|}{$\begin{array}{l}\text { Multiple occupa- } \\
\text { tions including } \\
\text { paid labor } \\
\text { (ref.) }\end{array}$} \\
\hline Student & & $0.269(0.200)$ & & $0.104(0.087)$ \\
\hline $\begin{array}{c}\text { Retired and other } \\
\text { unemployed }\end{array}$ & & $0.152(0.151)$ & & $0.039(0.061)$ \\
\hline \multicolumn{5}{|c|}{ Car availability $\times$ Fcycle } \\
\hline \multicolumn{5}{|c|}{ Always a car available (ref.) } \\
\hline $\begin{array}{l}\text { Not always a car } \\
\text { available }\end{array}$ & & $0.0978(0.135)$ & & $-0.008(0.057)$ \\
\hline No car available & & $-0.142(0.156)$ & & $-0.082(0.063)$ \\
\hline \multicolumn{5}{|l|}{$\begin{array}{l}\text { Urbanization } \\
\text { level } \times \text { Fcycle }\end{array}$} \\
\hline $\begin{array}{l}\text { Very highly } \\
\text { urbanized }\end{array}$ & & $0.213(0.151)$ & & $0.133 * *(0.063)$ \\
\hline Highly urbanized & & $0.105(0.133)$ & & $0.043(0.056)$ \\
\hline $\begin{array}{l}\text { Moderately } \\
\text { urbanized }\end{array}$ & & $0.292 * *(0.146)$ & & $0.082(0.060)$ \\
\hline \multicolumn{5}{|c|}{ Less urbanized/rural area (ref.) } \\
\hline Fbus $\times$ Fcycle & & $0.0144(0.051)$ & & $-0.0002(0.021)$ \\
\hline FCar $\times$ Fcycle & & $-0.0190(0.051)$ & & $-0.012(0.021)$ \\
\hline FTrain $\times$ Fcycle & & $-0.0288(0.046)$ & & $-0.014(0.020)$ \\
\hline
\end{tabular}


Table 4 (continued)

\begin{tabular}{|c|c|c|c|c|}
\hline \multirow[t]{2}{*}{ Variables } & \multicolumn{2}{|l|}{ Bicycle usage } & \multicolumn{2}{|c|}{ Cycling duration } \\
\hline & $\begin{array}{l}\text { Model 3a } \\
\text { Coef. (S.E.) }\end{array}$ & $\begin{array}{l}\text { Model 3b } \\
\text { Coef. (S.E.) }\end{array}$ & $\begin{array}{l}\text { Model 4a } \\
\text { Coef. (S.E.) }\end{array}$ & $\begin{array}{l}\text { Model 4b } \\
\text { Coef. (S.E.) }\end{array}$ \\
\hline \multicolumn{5}{|l|}{ Model fit } \\
\hline Log-likelihood & -1568.0429 & -1546.1000 & -1974.0220 & -1955.7158 \\
\hline $\begin{array}{l}\text { Ps.R2 (McFad- } \\
\text { den) }\end{array}$ & 0.1184 & 0.131 & 0.098 & 0.106 \\
\hline
\end{tabular}

Sig. codes: $* p \leq 0.1 ; * * p \leq 0.05 ; * * * p \leq 0.01$

${ }^{\mathrm{a}}$ Factor of attitudes toward bus

${ }^{\mathrm{b}}$ Factor of attitudes toward cycling

${ }^{\mathrm{c}}$ Factor of attitudes toward car

${ }^{\mathrm{d}}$ Factor of attitudes toward train

\section{Conclusions}

Although cycling behavior is often believed to be influenced by both environmental and individual factors, little is known about the interaction effects of travel mode attitudes in the association between demographic characteristics, urbanization level, and cycling behavior. The present study therefore examined the interaction effects of attitude toward cycling and sociodemographic characteristics and urbanization level on cycling duration/usage for commuting and other purposes among Dutch adults. Our findings provide partial support for the interactions between environmental and individual factors in relation to cycling behavior, as postulated by socioecological models (Sallis et al. 2015). The results showed that a positive attitude toward cycling was positively related to bicycle commuting duration, and that this association was less strong among those with a positive attitude toward the use of buses. Having a positive cycling attitude had a weaker positive effect on both bicycle commuting usage and duration in those who not always have a car available. Regarding cycling for other purposes, cycling attitude had a stronger positive association with cycling duration among residents of very highly urbanized area, compared to residents of less urbanized areas. The middle aged, the elderly and women with a positive attitude toward cycling were more likely to cycle in their day-to-day lives than their counterparts without a positive attitude toward cycling.

Overall, the study provides evidence for competitive mechanisms in which a positive cycling attitude is positively related to bicycle commuting duration, while this association is less strong among those with a positive attitude toward bus use. It also suggests the existence of synergetic mechanisms, in which a positive cycling attitude reinforces favorable cycling conditions (urban areas) or groups likely to cycle (elderly and women). On the other hand, compensatory mechanisms were found in that having a positive attitude toward cycling, had a weaker positive effect on bicycle commuting usage and duration among those who not always have a car available. While both competitive and synergetic mechanisms seem to exist, they translate into cycling behavior to only a limited extent.

To our knowledge, our study is the first to investigate the interaction effects of attitude toward cycling and sociodemographic characteristics, urbanization level, and attitude toward alternative travel modes on bicycle commuting and cycling for other purposes. The inclusion of attitudes toward other transportation modes is one of its strengths, indicating the possible competition between cycling and riding a bus. Another strength is the 
comparison of the usage and duration of bicycle commuting with that of cycling for other purposes. This makes the results more generalizable and indicates differences in correlates by cycling purpose, because the behavior of and decisions made by cyclists differ depending on trip purpose, especially for commuting and other purposes. Obviously, although the results are promising, they should be confirmed in future studies.

However, this study also has some limitations. First, data covering 1 year cannot be used to identify directionality in the relationship between attitudes and cycling patterns. Longitudinal studies measuring people's attitudes before and after changes in relation to cycling behavior would be valuable in understanding the relationships among attitudes, environmental factors, and cycling behavior. A second study limitation is that more nuanced physical environmental characteristics are needed, such as of the cycling infrastructure, which may be in relation to cycling behavior and attitudes. Furthermore, since cycling levels vary substantially among countries, additional research is needed to determine to what extent the impact of cycling attitude depends on the specific local context.

For policy making, our results highlight the complex link between attitudinal and contextual factors, showing that, to optimize interventions to increase bicycle use, both factors should be targeted simultaneously. A better understanding of the interactions between attitudinal factors and contextual factors could be beneficial for the tailoring of intervention strategies to specific population groups, as well as may contribute to the development of multi-level interventions (Ding et al. 2012). For example, the available evidence, suggests that targeting attitudes (e.g., via social marketing campaigns) can have a measurable impact on cycling (Pucher et al. 2010), but the effect may differ between specific geographical or socio-demographic strata. Further, this work points to target groups that deserve attentions in future studies (e.g., families with young children) to find out which barriers they face for bicycling, and how these could be overcome. Our findings contribute to the knowledge of how multiple factors may reciprocate to influence an individual's decision to cycle.

Authors' contribution JG conceived the specific study described in this paper, coordinated the data collection, performed the statistical analyses, and drafted the manuscript. DE, CBMK, and MH provided critical input for the data analyses and helped draft the manuscript. All authors read and approved the final manuscript.

\section{Compliance with ethical standards}

Conflict of interest On behalf of all authors, the corresponding author states that there is no conflict of interest.

Open Access This article is distributed under the terms of the Creative Commons Attribution 4.0 International License (http://creativecommons.org/licenses/by/4.0/), which permits unrestricted use, distribution, and reproduction in any medium, provided you give appropriate credit to the original author(s) and the source, provide a link to the Creative Commons license, and indicate if changes were made.

\section{Appendix}

See Table 5. 


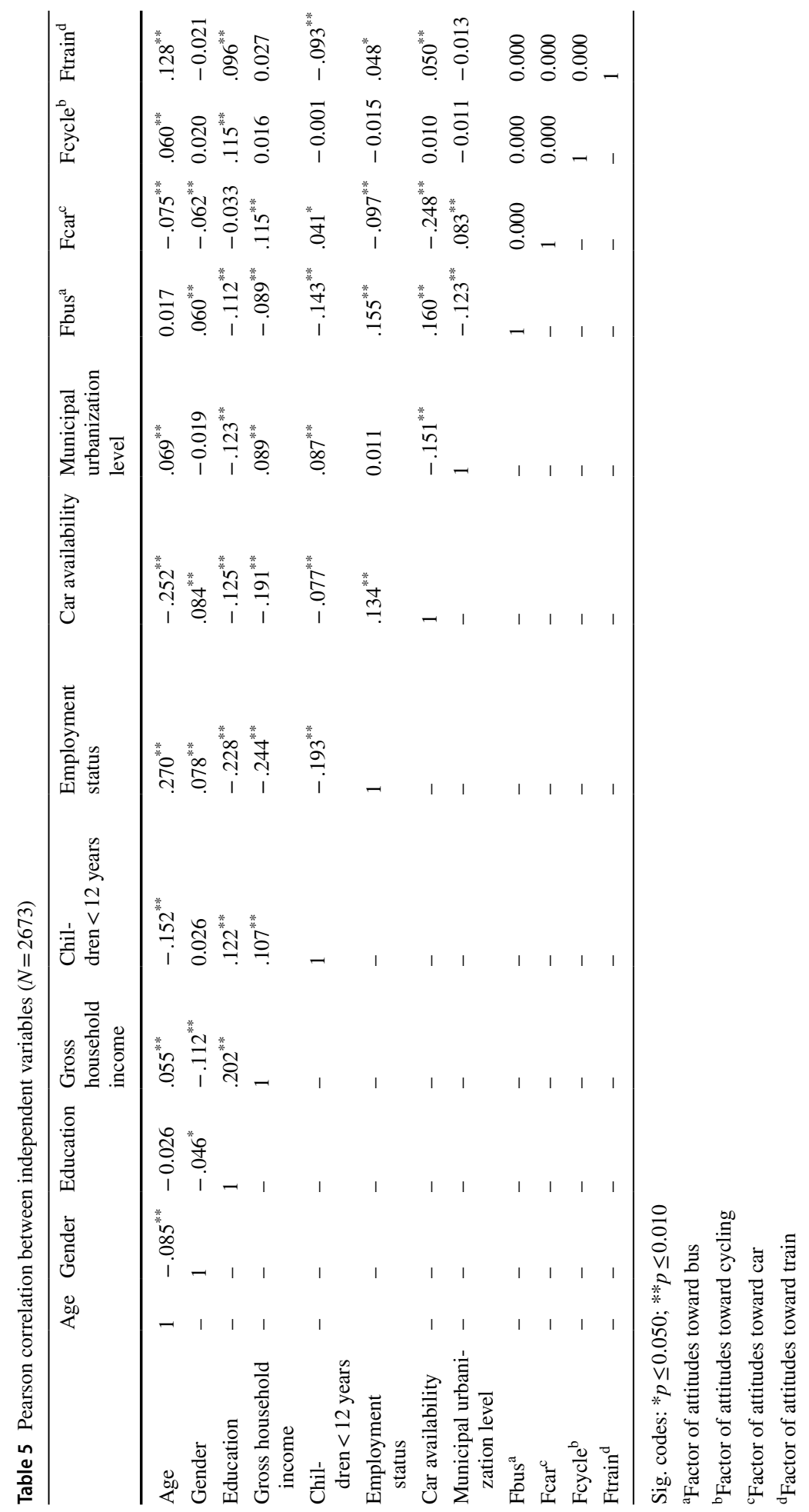




\section{References}

Ajzen, I.: The theory of planned behavior. Organ. Behav. Hum. Decis. Process. 50(2), 179-211 (1991)

Barnes, G., Krizek, K.: Estimating bicycling demand. Transp. Res. Rec. J. Transp. Res. Board 1939, 45-51 (2005)

Beenackers, M.A., Kamphuis, C.B., Mackenbach, J.P., Burdorf, A., van Lenthe, F.J.: Why some walk and others don't: exploring interactions of perceived safety and social neighborhood factors with psychosocial cognitions. Health Educ. Res. 28(2), 220-233 (2013)

Beenackers, M.A., Kamphuis, C.B., Prins, R.G., Mackenbach, J.P., Burdorf, A., van Lenthe, F.J.: Urban form and psychosocial factors: do they interact for leisure-time walking? Med. Sci. Sports Exerc. 46(2), 293-301 (2014)

Bhat, C.R., Guo, J.Y.: A comprehensive analysis of built environment characteristics on household residential choice and auto ownership levels. Transp. Res. Part B Methodol. 41(5), 506-526 (2007)

Bourke, M., Hilland, T.A., Craike, M.: An exploratory analysis of the interactions between social norms and the built environment on cycling for recreation and transport. BMC Public Health 18(1), 1162 (2018)

Bryant, F.B., Yarnold, P.R.: Principal-components analysis and exploratory and confirmatory factor analysis In: Grimm, L.G., Yarnold, P.R. (eds.) Reading and Understanding Multivariate Statistics, pp. 99-136. American Psychological Association, Washington, DC (1995)

Cao, X., Handy, S.L., Mokhtarian, P.L.: The influences of the built environment and residential self-selection on pedestrian behavior: evidence from Austin, TX. Transportation 33(1), 1-20 (2006). https://doi. org/10.1007/s11116-005-7027-2

Cao, X., Mokhtarian, P.L., Handy, S.L.: Examining the impacts of residential self-selection on travel behaviour: a focus on empirical findings. Transp. Rev. 29(3), 359-395 (2009)

Carlson, J.A., Sallis, J.F., Conway, T.L., Saelens, B.E., Frank, L.D., Kerr, J., Cain, K.L., King, A.C.: Interactions between psychosocial and built environment factors in explaining older adults' physical activity. Prev. Med. 54(1), 68-73 (2012)

CBS: Educational attainment. http://statline.cbs.nl/Statweb/selection/?DM=SLNL\&PA=82275 NED\&VW=T (2016). Accessed 16 Feb 2016

Cervero, R., Kockelman, K.: Travel demand and the 3Ds: density, diversity, and design. Transp. Res. Part D Transp. Environ. 2(3), 199-219 (1997)

Curto, A., De Nazelle, A., Donaire-Gonzalez, D., Cole-Hunter, T., Garcia-Aymerich, J., Martínez, D., Anaya, E., Rodríguez, D., Jerrett, M., Nieuwenhuijsen, M.J.: Private and public modes of bicycle commuting: a perspective on attitude and perception. Eur. J. Publ. Health 26(4), 717-723 (2016)

D’Haese, S., Gheysen, F., De Bourdeaudhuij, I., Deforche, B., Van Dyck, D., Cardon, G.: The moderating effect of psychosocial factors in the relation between neighborhood walkability and children's physical activity. Int. J. Behav. Nutr. Phys. Activity 13(1), 128 (2016)

de Haas, M., Scheepers, C., Harms, L., Kroesen, M.: Travel pattern transitions: applying latent transition analysis within the mobility biographies framework. Transp. Res. Part A Policy Pract. 107, 140-151 (2018)

de Nazelle, A., Nieuwenhuijsen, M.J., Antó, J.M., Brauer, M., Briggs, D., Braun-Fahrlander, C., Cavill, N., Cooper, A.R., Desqueyroux, H., Fruin, S., Hoek, G., Panis, L.I., Janssen, N., Jerrett, M., Joffe, M., Andersen, Z.J., van Kempen, E., Kingham, S., Kubesch, N., Leyden, K.M., Marshall, J.D., Matamala, J., Mellios, G., Mendez, M., Nassif, H., Ogilvie, D., Peiró, R., Pérez, K., Rabl, A., Ragettli, M., Rodríguez, D., Rojas, D., Ruiz, P., Sallis, J.F., Terwoert, J., Toussaint, J.-F., Tuomisto, J., Zuurbier, M., Lebret, E.: Improving health through policies that promote active travel: a review of evidence to support integrated health impact assessment. Environ. Int. 37(4), 766-777 (2011). https://doi. org/10.1016/j.envint.2011.02.003

De Vos, J., Witlox, F.: Do people live in urban neighbourhoods because they do not like to travel? Analysing an alternative residential self-selection hypothesis. Travel Behav. Soc. 4, 29-39 (2016)

Diana, M., Mokhtarian, P.L.: Grouping travelers on the basis of their different car and transit levels of use. Transportation 36(4), 455-467 (2009)

Dill, J., Mohr, C., Ma, L.: How can psychological theory help cities increase walking and bicycling? J. Am. Plann. Assoc. 80(1), 36-51 (2014)

Dill, J., Voros, K.: Factors affecting bicycling demand: initial survey findings from the Portland, Oregon, region. Transp. Res. Rec. J. Transp. Res. Board 2031, 9-17 (2007)

Ding, D., Sallis, J.F., Conway, T.L., Saelens, B.E., Frank, L.D., Cain, K.L., Slymen, D.J.: Interactive effects of built environment and psychosocial attributes on physical activity: a test of ecological models. Ann. Behav. Med. 44(3), 365-374 (2012)

Ettema, D., Nieuwenhuis, R.: Residential self-selection and travel behaviour: what are the effects of attitudes, reasons for location choice and the built environment? J. Transp. Geogr. 59, 146-155 (2017) 
Ewing, R., Cervero, R.: Travel and the built environment: a meta-analysis. J. Am. Plann. Assoc. 76(3), 265294 (2010)

Fishman, E., Böcker, L., Helbich, M.: Adult active transport in the Netherlands: an analysis of its contribution to physical activity requirements. PloS ONE 10(4) (2015a). https://doi.org/10.1371/journ al.pone.0121871

Fishman, E., Schepers, P., Kamphuis, C.B.M.: Dutch cycling: quantifying the health and related economic benefits. Am. J. Publ. Health 105(8), e13-e15 (2015). https://doi.org/10.2105/AJPH.2015.302724

Freedman, D., Pisani, R., Purves, R., Adhikari, A.: Statistics, 2nd edn. Norton, New York (1991)

Fu, L., Farber, S.: Bicycling frequency: a study of preferences and travel behavior in Salt Lake City, Utah. Transp. Res. Part A: Policy Pract 101, 30-50 (2017)

Gao, J., Helbich, M., Dijst, M., Kamphuis, C.: Socioeconomic and demographic differences in walking and cycling in the Netherlands - How do these translate into differences in health benefits? J. Transp. Health 6, 358-365 (2017)

Gao, J., Kamphuis, C.B., Dijst, M., Helbich, M.: The role of the natural and built environment in cycling duration in the Netherlands. Int. J. Behav. Nutr. Phys. Activity 15(1), 82 (2018)

Garrard, J., Rose, G., Lo, S.K.: Promoting transportation cycling for women: the role of bicycle infrastructure. Prev. Med. 46(1), 55-59 (2008). https://doi.org/10.1016/j.ypmed.2007.07.010

Gatersleben, B., Uzzell, D.: Affective appraisals of the daily commute: comparing perceptions of drivers, cyclists, walkers, and users of public transport. Environ. Behav 39(3), 416-431 (2007)

Greene, W.H.: Econometric Analysis. Pearson Education India, New York (2003)

Härdle, W., Simar, L.: Applied Multivariate Statistical Analysis, vol. 22007. Springer, Berlin (2007)

Hair, J.F., Black, W.C., Babin, B.J., Anderson, R.E.: Multivariate Data Analysis. Pearson Prentice Hall, New York (2009)

Handy, S., Van Wee, B., Kroesen, M.: Promoting cycling for transport: research needs and challenges. Transp. Rev. 34(1), 4-24 (2014)

Handy, S.L., Xing, Y., Buehler, T.J.: Factors associated with bicycle ownership and use: a study of six small U.S. cities. Transportation 37(6), 967-985 (2010). https://doi.org/10.1007/s11116-010-9269-X

Heinen, E., Maat, K., Van Wee, B.: The role of attitudes toward characteristics of bicycle commuting on the choice to cycle to work over various distances. Transp. Res. Part D Transp. Environ. 16(2), 102-109 (2011)

Heinen, E., Van Wee, B., Maat, K.: Commuting by bicycle: an overview of the literature. Transp. Rev.s 30(1), 59-96 (2010)

Hoogendoorn-Lanser, S., Schaap, N.T., OldeKalter, M.-J.: The Netherlands Mobility Panel: an innovative design approach for web-based longitudinal travel data collection. Transp. Res. Proced. 11, 311-329 (2015)

Miller, J., Handy, S.: Factors that influence university employees to commute by bicycle. Transp. Res. Rec. J. Transp. Res. Board 2314, 112-119 (2012)

Oakil, A.T.M., Ettema, D., Arentze, T., Timmermans, H.: Bicycle Commuting in the Netherlands: an analysis of modal shift and its dependence on life cycle and mobility events. Int. J. Sustain. Transp. 10(4), 376-384 (2016)

Oja, P., Titze, S., Bauman, A., De Geus, B., Krenn, P., Reger-Nash, B., Kohlberger, T.: Health benefits of cycling: a systematic review. Scand. J. Med. Sci. Sports 21(4), 496-509 (2011)

Piatkowski, D.P., Marshall, W.E.: Not all prospective bicyclists are created equal: the role of attitudes, sociodemographics, and the built environment in bicycle commuting. Travel Behav. Soc. 2(3), 166-173 (2015)

Pucher, J., Buehler, R.: Making cycling irresistible: lessons from the Netherlands, Denmark and Germany. Transp. Rev. 28(4), 495-528 (2008). https://doi.org/10.1080/01441640701806612

Pucher, J., Dill, J., Handy, S.: Infrastructure, programs, and policies to increase bicycling: an international review. Prev. Med. 50, S106-S125 (2010)

Sallis, J.F., Owen, N., Fisher, E.: Ecological Models of Health Behavior. Health Behavior: Theory, Research, and Practice, 5th edn, pp. 43-64. Jossey-Bass, San Francisco (2015)

Scheepers, E., Wendel-Vos, W., van Kempen, E., Panis, L.I., Maas, J., Stipdonk, H., Moerman, M., den Hertog, F., Staatsen, B., van Wesemael, P., Schuit, J.: Personal and Environmental Characteristics Associated with Choice of Active Transport Modes versus Car Use for Different Trip Purposes of Trips up to 7.5 Kilometers in The Netherlands. PloS One 8(9) (2013). https://doi.org/10.1371/journal.pone.00731 05

Schwanen, T., Mokhtarian, P.L.: What affects commute mode choice: neighborhood physical structure or preferences toward neighborhoods? J. Transp. Geogr. 13(1), 83-99 (2005). https://doi.org/10.1016/j. jtrangeo.2004.11.001

Stinson, M., Bhat, C.: Frequency of bicycle commuting: internet-based survey analysis. Transp. Res. Rec. J. Transp. Res. Board 1878, 122-130 (2004) 
Wang, X., Conway, T.L., Cain, K.L., Frank, L.D., Saelens, B.E., Geremia, C., Kerr, J., Glanz, K., Carlson, J.A., Sallis, J.F.: Interactions of psychosocial factors with built environments in explaining adolescents' active transportation. Prev. Med. 100, 76-83 (2017)

Willis, D.P., Manaugh, K., El-Geneidy, A.: Cycling under influence: summarizing the influence of perceptions, attitudes, habits, and social environments on cycling for transportation. Int. J. Sustain. Transp. 9(8), 565-579 (2015)

Wong, B.Y.-M., Faulkner, G., Buliung, R.: GIS measured environmental correlates of active school transport: a systematic review of 14 studies. Int. J. Behav. Nutr. Phys. Activity 8(1), 39 (2011)

Wooldridge, J.M.: Econometric Analysis of Cross Section and Panel Data. MIT Press, Cambridge (2010)

Xing, Y., Handy, S.L., Mokhtarian, P.L.: Factors associated with proportions and miles of bicycling for transportation and recreation in six small US cities. Transp. Res. Part D: Transp. Environ. 15(2), 73-81 (2010)

Xing, Y., Volker, J., Handy, S.: Why do people like bicycling? Modeling affect toward bicycling. Transp. Res. Part F: Traffic Psychol. Behav. 56, 22-32 (2018)

Yang, L., Shen, Q., Li, Z.: Comparing travel mode and trip chain choices between holidays and weekdays. Transp. Res. Part A: Policy Pract. 91, 273-285 (2016)

Publisher's Note Springer Nature remains neutral with regard to jurisdictional claims in published maps and institutional affiliations.

Jie Gao is Ph.D student in the Department of Human Geography and Spatial Planning of Utrecht University. Her research mainly focuses on active travel and public health, especially the relations between environmental factors and walking/cycling, and how these relations differ regarding city size, attitudinal factors, life events.

Dick Ettema is professor of Urban Accessibility and Social Inclusion in the Department of Human Geography and Spatial Planning in Utrecht University. His research focuses on how the accessibility of cities and urban regions changes as a result of demographic, economic, societal and technological developments, and how this affects citizens' daily activity and travel patterns and their social inclusion.

Marco Helbich is associate professor in the Department of Human Geography and Spatial Planning, Utrecht University. His research deals with how cities function and how the built and natural environments affect human behavior. His research interests focus on geocomputational techniques and spatio-temporal analytics to address human-environment relations in cities.

Carlijn B. M. Kamphuis is associate professor of Public Health at the Department of Interdisciplinary Social Science of Utrecht University. Her research focuses on socioeconomic inequalities in health and healthbehaviors, and the role of characteristics of the physical and social environment.

\section{Affiliations}

\section{Jie Gao ${ }^{1}$ (D) $\cdot$ Dick Ettema $^{1} \cdot$ Marco Helbich $^{1} \cdot$ Carlijn B. M. Kamphuis ${ }^{2}$}

Dick Ettema

D.F.Ettema@uu.nl

Marco Helbich

M.Helbich@uu.nl

Carlijn B. M. Kamphuis

C.B.M.Kamphuis@uu.nl

1 Department of Human Geography and Spatial Planning, Faculty of Geosciences, Utrecht University, Princetonlaan 8a, 3584 CB Utrecht, The Netherlands

2 Department of Interdisciplinary Social Science, Faculty of Social and Behavioral Sciences, Utrecht University, Heidelberglaan 1, 3584 CS Utrecht, The Netherlands 